Article

\title{
Antecedents of Self-Disclosure on Social Networking Sites (SNSs): A Study of Facebook Users
}

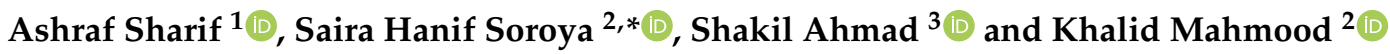 \\ 1 Systems Librarian, Aga Khan University, Karachi 74800, Pakistan; ashraf.sharif@aku.edu \\ 2 Department of Information Management, University of the Punjab, Lahore 54590, Pakistan; \\ khalid.im@pu.edu.pk \\ 3 Research Services Librarian, Prince Sultan University, Riyadh 66833, Saudi Arabia; shakil@psu.edu.sa \\ * Correspondence: saira.im@pu.edu.pk
}

check for

updates

Citation: Sharif, A.; Soroya, S.H.; Ahmad, S.; Mahmood, K Antecedents of Self-Disclosure on Social Networking Sites (SNSs):

A Study of Facebook Users.

Sustainability 2021, 13, 1220.

https://doi.org/10.3390/su13031220

Received: 26 November 2020

Accepted: 21 January 2021

Published: 25 January 2021

Publisher's Note: MDPI stays neutral with regard to jurisdictional claims in published maps and institutional affiliations.

Copyright: (c) 2021 by the authors. Licensee MDPI, Basel, Switzerland. This article is an open access article distributed under the terms and conditions of the Creative Commons Attribution (CC BY) license (https:// creativecommons.org/licenses/by/ $4.0 /)$.

\begin{abstract}
Self-disclosure on social networking sites (SNSs) leads to social capital development, connectedness, and relationship building. Due to several benefits associated with this behavior self-disclosure has become a subject of research over the last few years. The current study investigates the antecedents of self-disclosure under the lens of the technology acceptance model (TAM). The research is quantitative, and the data were collected from 400 Pakistani Facebook users with a variety of demographic characteristics. The partial least squares-structural equation model (PLS-SEM) analysis technique was employed to analyze the data. The study's findings confirmed that perceived usefulness is a strong predictor of personal information sharing, and it along with other variables causes a $31 \%$ variation in self-disclosure behavior. However, trust (medium and social) mediates the relationshipof perceived usefulness, privacy concerns, and self-disclosure behavior.
\end{abstract}

Keywords: self-disclosure; personal information sharing; social networking sites; TAM; Pakistan

\section{Introduction}

The introduction of the Internet has been integral to information sharing. Before 1995, the Internet was predominantly used by large corporations and academia to exchange information in the form of research. The Internet has transfigured the world of computers and communication through its ability to transmit data, and as an instrument of information sharing [1]. It took many years for the current variation of social networks to the to evolve. Some of the social networking sites (SNSs) took shape in the 1990s, like BlackPlanet, MoveOn, Six Degrees, Asian Avenue, etc. However, social media was fostered in 2000 when many SNSs flourished and revolutionized communication between individuals and groups who started sharing their social-network-based common interests in education, music, movies, and friendship [2].

Mark Zuckerberg launched Facebook on 4 February 2004. Dustin Moskovitz, Chris Hughes, and Eduardo Saverin were co-founders of this venture. In September of the same year, they introduced 'Facebook Wall', where people could post messages for their friends. Following this, within a short period of three months, one million people were active [3].

In contrast, the number of users of different social networking sites (SNSs) worldwide has also increased by 280 million since January 2018 [4]. AlQadheeb and Alsalloum [5] stated that $94 \%$ of Internet users had their accounts on at least one social media platform. Global Web Index [6] reported that six of 10 global Internet users were connected continuously online in 2019. Facebook has been the most famous social networking site. The data shows that the number of monthly active Facebook users reached 2.5 billion globally as of the 4th quarter of 2019 [7]. This number is exponentially increasing, and there were over 2.7 billion Facebook users globally, with an active account monthly as of 30 June 2020. This was an increase of 12 percent in Facebook monthly active users year-over-year [8]. 
Almost every SNS is meant for sharing, uploading, viewing, downloading, and understanding the information. The common purposes for information sharing are to get others' attention, develop social capital, strengthen relationships among individuals, attract like-minded people, and develop information and knowledge-based societies. The SNSs users usually create a profile and put their information on these sites, most of which are personal [9]. This profile could require personal and/or private information, i.e., name, photos, e-mail, physical/mailing address, cellular phone numbers, gender, interests, etc. However, some users share this information by choice on these sites, as these sites have an option to add more personal information like photographs, videos, family information, preferences, events, stories, opinions, etc. [10].

In postmodern times, the sharing of personal information on social media networks has become excessively simple. Many platforms are readily available for people willing to share their personal information on social media, particularly on the most popular platform, Facebook. The terms 'self-disclosure' and 'personal information sharing' are used interchangeably in the literature. Self-disclosure is defined as 'the act of revealing personal information to others' [11]. In the context of business, personal information sharing behavior is described by the perception of information disclosure, which eventually refers to revealing consumers' data, i.e., biographical and/or demographic attributes, way of living, shopping practices, likes of commercial organizations [12,13] In general, posting a picture, personal information, providing status updates, or revealing personal preferences and experiences while engaging in public communication with other online community members is known as self-disclosure [14]. Certain factors impact personal information sharing behavior or self-disclosure, e.g., social trust, trust, enjoyment, ease of use, benefits [15-17], and privacy concerns [18,19].

Self-disclosure is mostly associated with social capital development [20] and interpersonal relationship building [21]. Literature suggests that self-disclosure helps individuals to overcome feelings of loneliness [22]. Thus, it can positively impact the individual's well-being [23,24]. Lately, during the COVID-19 emergency, people were socially isolated, and at this time, social capital could help individuals feel connected with others and reduce loneliness. Nabity-Grover et al. [25] found a significant positive impact of COVID-19 on individual's self-disclosure behavior, and they were found involved in self-disclosure on social media. The research on this topic mostly comes from developed countries, i.e., United States [16,26,27] (Saudi Arabia [5], Dutch [18], Turkey [28], Germany and Norway [29], Malaysia [30], and Hong Kong [31], etc. However, little is known from developing countries, i.e., Indonesia [32], Brazil [33], while no literature could be found from South Asian contexts regarding self-disclosure. Only one study based on Pakistani students' self-disclosure behavior is reported recently from China. Developing countries usually lack resources and expertise in different areas; therefore, it is essential to research developing countries to identify the current status, challenges, and opportunities to devise viable frameworks. In the modern digital paradigm, the effective use of information technology can help developing countries deal with several challenges, particularly those concerning the current research. Technology adoption in terms of self-disclosure may help overcome anxiety, depression, and mental ill-being of individuals through social capital development and connectedness. The identified antecedents may be manipulated effectively to bring positive outcomes.

Considering this literature gap, the current research was carried out to explore Pakistani Facebook users' self-disclosure behavior and the factors that encourage them to share their personal information. The findings may be helpful to understand the phenomena in the local context in a comprehensive way. The results will further help identify the antecedents that, if utilized in a planned way, can positively affect self-disclosure behavior, which may further positively affect an individual's well-being and help them develop social capital. 


\section{Background}

\subsection{Self-Disclosure}

Self-disclosure is a concept that came from the field of psychology and has actively been studied since the 1970s, along with its closer disciplines, like social science and communication science [34]. It has been defined as "verbally communicating personal information about the self to another person" [35]. Whereas Pearce and Sharp [36] refer to the communication behavior through which the speaker consciously makes him/herself known to the other persons. Recently, Bazarova and Choi [37] called it a public disclosure that could be shared on a social networking site or with a network of friends or followers. Normally, self-disclosure behaviors encompass revealing information regarding oneself to others [38]. Several researchers have defined self-disclosure as the revelation of one's private information to others. It provides identity by creating a profile to share personal information, emotions, pictures, and updates. It is a demonstration of uncovering individual information to other people. A social marvel can be the act of delivering any data about oneself to someone else. Self-disclosure behavior is measured by how many users' profiles are packed with their data and how much data users disclose on social networking sites. It is related to the sharing of individual-specific and personally identifiable information (PII). Personal information behavior or self-disclosure has been grabbing the attention of researchers. Several studies have been conducted in different parts of the world to identify the predictors and antecedents of self-disclosure [11,39-43]. After a thorough literature review, the researchers selected the following five antecedents found influencing self-disclosure in one way or the other.

\subsection{Perceived Ease of Use}

Perceived ease of use alludes to the extent to which a user utilizes a specific technology, connects to different websites, and finds Internet operations easy to use [44]. Venkatesh [45] termed it as a construct that was attached to anyone's evaluation of the efforts he or she puts into the process of using a system. It is about the perception of essential technological components [46]. Concerning personal information sharing, there are two sets of studies; one supports Davis's [44] philosophy that perceived ease of use positively impacts personal information sharing behavior $[47,48]$. Whereas the other group of researchers believes that there is no correlation between perceived ease of use and information sharing [17] However, in the Pakistani context, Pitafi et al. [49] found that ease of use significantly impacts students' social networking sites addiction.

\subsection{Perceived Usefulness}

Typically, perceived usefulness is defined as the degree to which a person believes that using a particular system would enhance their job performance [44]. In the context of social networking sites, the perceived usefulness (benefits) can be described as maintaining the existing relations, developing new relationships, self-presentation, and enjoyment of the social networking sites [5]. Perceived usefulness has proven a strong predictor of personal information sharing behavior on social networking sites among the younger generation [15]. Anticipated advantages (usefulness) significantly influence the readiness to reveal personal information [18]. Zhou [50] also noted that perceived usefulness positively influenced people's personal information disclosure behavior in online health communities. A very recent study [51] showed that users' perceptions of recommended systems' overall relevance correlated with their data sharing acceptance and perceived usefulness. However, McKnight et al. [52] could not find any influence of perceived usefulness on information disclosure on Facebook.

\subsection{Perceived Risk/Privacy Concerns}

Privacy has been defined as a personal boundary regulation process to regulate privacy levels with others, depending on the context [53]. Whereas privacy concerns measure if the users are concerned about who will have access to the information they put on SNSs [43]. 
Privacy concerns can also be alluded to as risks that reflect the social networking sites (SNSs) users' concerns on their personal data secrecy on a website. Privacy concerns are ones' intrinsic fears about secrecy's potential damage due to information disclosure to a particular external actor $[12,54]$. The presence of a privacy paradox is often declared if there is no relationship between users' information privacy concerns and their online self-disclosure [55] (Gruzd and Hernández-García, 2018).

Privacy concerns have a negative correlation with self-disclosure [26,28]. However, this impact varies in different contexts; for example, Beuker [18] established that privacy concerns have less influence on the willingness to disclose personal information in Dutch Facebook users. Contrarily, in a very recent study, Zhang and Fu [31] found that the volume, intimacy, and honesty of self-disclosure on social networking sites have been adversely associated with privacy concerns. Similarly, Kalmer and Schultheiss [29] carried out a cross-cultural comparison of Germans and Norwegian Facebook users on privacy and personal information disclosure. They found that privacy concerns and attitudes have an indirect effect on personal information sharing or self-disclosure.

\subsection{Trust in Medium}

The notion of trust is not new. It has been widely accepted as a key element of human social relations. Trust has been studied in various academic areas that include psychology, sociology, philosophy, history politics, economics, computer science, etc. Trust is defined differently in different disciplines [56]. Sociologists define trust as a set of expectations held by individuals involved in an exchange [57]. From the marketing perspective, trust is defined as the supposed reliability and goodwill of the target of trust [58]. In the context of social networking sites, trust in the website has been termed as the willingness of a user to be reliant on the site [59]. Trust in a website was also referred to by Wu and Chang [60] as an imperative aspect of influencing consumers' buying decisions. It has been defined as a person's belief in the abilities, trustworthiness, and reliability of others [61].

In relation to self-disclosure, Chang and Heo [62] found that users' trust in the medium, especially on Facebook, affects users' self-disclosure behavior. This argument is further supported by $[16,32]$. Both found in their studies that trust positively and significantly affected sharing personal data on social networking sites.

\subsection{Social Trust}

Social trust has been defined as "the firm belief in the competence of an entity to act as expected, such that this firm belief is not a fixed value associated with the entity, but rather it is subject to the entity's behavior and applies only within a specific context at any given time" [56]. Koranteng et al. [63] stated that their mutual responses define the colleagues' honesty and reliability, and students are more tending to trust others from whom they expect to receive support. Social trust in social networking sites had a stronger control on social media information through the intention of social media use [47]. It is also positively associated with the attitude towards self-disclosure or personal information sharing [16]. Social trust strengthens individuals' trust in social network sites [27].

\section{Theoretical Foundations}

\subsection{Theoretical Framework}

The Technology Acceptance Model (TAM) was used to carry out this study. Based on the reasoned action theory [64], Davis developed TAM in 1989. TAM's main philosophy is that perceived ease of use and perceived usefulness are primary factors of technology adoption. This model has largely been applied to study technology acceptance intention and behavior [65-68]. Ajibade [69] (2018) conducted a literature review and discussed the criticism and limitations of the Technology Acceptance Model, i.e., TAM cannot be successfully applied in organizations and institutions to study employees' technology adoption behavior. The reason behind this limitation is that they usually work on systems, and it is their job requirement to learn the technology. Secondly, they receive forceful 
influence from their seniors to adopt a technology. However, this framework is applicable to study individuals' behavior who are not particularly a part of an organization or institution [69]. Since the current study represents the general public (not from a specific work environment) who are Facebook users and represent different social groups, TAM was considered appropriate to understand Pakistani Facebook users' self-disclosure behavior. Furthermore, concerning self-disclosure in particular, earlier studies also adopted the TAM framework successfully to study the phenomena in different contexts [70,71].

\subsection{Hypotheses Development}

TAM suggests that if a technology or a medium is easy to use for people and does not require much effort to use it, they consider the technology/medium more useful. Literature has established a strong positive correlation between perceived ease of use of a technology/medium and individuals' perceptions about its usefulness. It is evident that customers find online shopping more beneficial if they can easily navigate the online store [72]. Similarly, it is argued that mobile marketers should make users' work easier if they intend to increase the perceived usefulness of technology and its adoption [65].

Hypotheses 1 (H1). Perceived ease of Facebook use has a significant positive impact on personal information sharing's perceived usefulness.

Humans adopt a certain behavior if they find it useful. Previous studies conducted underpinning the framework of TAM have confirmed this argument. A study conducted on Midwestern University students noted that the larger the perceived value of the benefits provided by certain websites were, the more Internet users might become willing to register with the website even if they needed to release their personal information [73]. Youth in the Netherlands expressed a strong perceived control over their intention to reveal personal data on online social networks if they find personal information sharing beneficial $[15,74]$.

Similarly, Beuker [18] conducted a study on German and Dutch Facebook users through an online survey and observed that the anticipated advantages significantly influence the readiness to reveal personal information. In the context of Saudi Arabia, AlQadheeb and Alsalloum [5] described the benefits of self-disclosure as maintaining the existing relations, developing new relationships, self-presentation, and enjoyment. They found that Saudi SNS users were motivated by these benefits to use the SNS and share their personal information. Since the studies conducted in different contexts corroborate each other's findings, the following hypothesis was developed.

Hypotheses 2 (H2). Perceived usefulness of personal information sharing positively impacts self-disclosure/personal information sharing behavior.

The users of a certain medium/technology possess trust towards it if they find it beneficial. In the context of mobile commerce, perceived usefulness is considered an important predictor of trust in a technology/medium $[75,76]$. People intend to initially use or to continue using technology or website if they consider it useful [77]. Similarly, users' satisfaction with mobile websites is found dependent on perceived usefulness through their trust [65]. Thus, the following hypothesis was developed:

Hypotheses 3 (H3). Perceived usefulness of self-disclosure has a significant positive impact on one's trust in a medium (Facebook).

On the contrary, if individuals have privacy concerns about a medium, it negatively affects that medium's trust. People will be reluctant to use that medium due to fear of privacy/security breaches. A study based on meta-analysis showed that higher privacy concerns were associated with weaker intentions to utilize online services [78]. Individuals believe that accessing social networking sites over the internet is secure and develops trust in the medium [79].

Hypotheses 4 (H4). Perceived risk/privacy concerns have a significant negative impact on one's trust in a medium (Facebook). 
It is evident that if individuals trust in a medium, they will also trust others who are members of that community. Waldman [80] explained trust in online sources uniquely and considered that trust is greatly relevant to social trust. Humans trust humans who are the members/users of a medium. They trust in a medium as they believe that if a medium has millions of users, how can it be wrong, and if there was any harm in using the online website, why would a large number of users be associated with it. Therefore, the following hypothesis is developed.

Hypotheses 5 (H5). Individuals' trust in the medium significantly impacts the development of social trust.

Trust in the information users is an important antecedent of self-disclosure. It is not only the medium that is related to privacy concerns, but the community that belongs to that particular medium should also be trustworthy for information sharing decisions. Studies conducted in different cultures and contexts found that social trust has a significant positive impact on social media use and personal information sharing behavior $[16,30,47,81]$ Therefore it is hypothesized that:

Hypotheses 6 (H6). Social trust has a significant positive impact on self-disclosure/personal information sharing behavior.

The hypothetical model is presented in Figure 1.

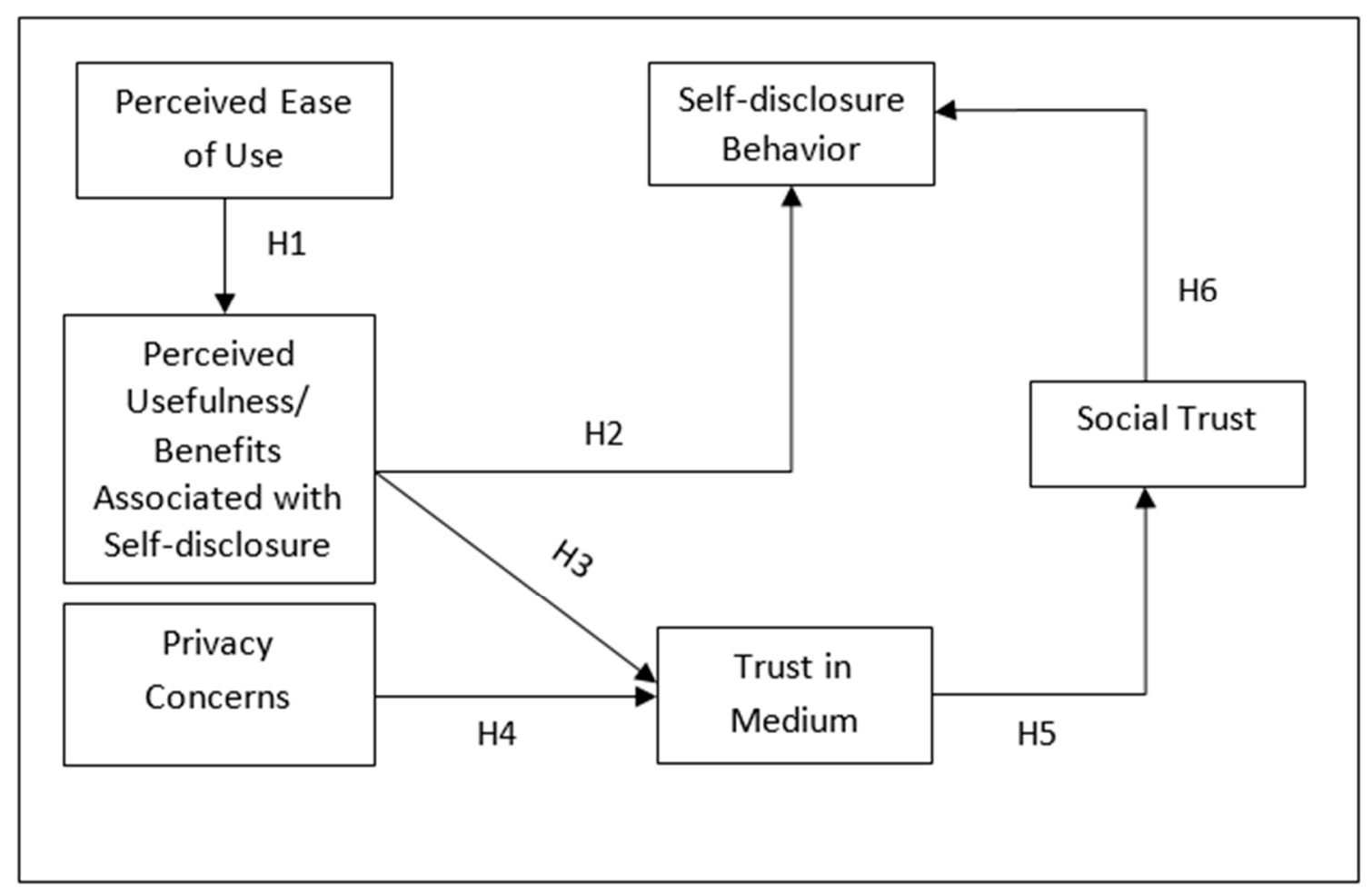

Figure 1. Proposed Hypothetical Model.

The constructs used in our hypothesized model are explained in Table 1. 
Table 1. Definition of Terms.

\begin{tabular}{cc}
\hline $\begin{array}{c}\text { Perceived Ease of Use } \\
\text { Perceived Usefulness (Benefits) }\end{array}$ & $\begin{array}{c}\text { The degree to which a person believes that using a particular system would be free } \\
\text { of effort [44] }\end{array}$ \\
\hline Privacy Concerns & $\begin{array}{r}\text { "The degree to which a person believes that using a particular system would } \\
\text { enhance his or her job performance" [44] }\end{array}$ \\
\hline Trust in Medium & $\begin{array}{r}\text { An individual belief in the ability of social networking sites that revealing } \\
\text { information and performing any task is risk-free [82] (Dhami et al., 2013) }\end{array}$ \\
\hline Social Trust & $\begin{array}{r}\text { An individual's belief that other users are trustworthy, care about their well-being, } \\
\text { and will not abuse their personal information [5] }\end{array}$ \\
\hline Self-Disclosure & $\begin{array}{c}\text { Posting a picture, personal information, providing status updates, or revealing } \\
\text { personal preferences and experiences while engaging in public communication } \\
\text { with other online community members is known as self-disclosure [14]. }\end{array}$ \\
\hline
\end{tabular}

\subsection{Research Procedures and Methods}

The quantitative research design employing questionnaire-based survey research methods was adopted to meet the research objectives. The population of this study consisted of all Pakistani Facebook users. A convenience sampling technique was applied to this study. The only required criterion to fill out the online form was that the respondents should be Facebook users. There were 31 million Facebook users in Pakistan in March 2019. The majority ( $81 \%$ ) of them were male users. The young people aged 18 to 24 years were the largest user group [83]. The size requirement does not change significantly if the population size is larger than 100,000 [84]. According to this formula, the calculated sample size was 385 , with a $5 \%$ margin of error.

A structured, closed-ended questionnaire was designed and used for this study (Appendix A Table A1). The survey instrument for this study was developed with the help of past research studies with slight changes in wording to match them with the study setting. The scale for the dependent variable 'Self-disclosure/Personal information sharing behavior' was adopted from a study conducted [16], which consisted of five statements. The next construct 'Trust in Medium' was picked from Sukhu et al. [17] with five statements. Similarly, the construct for the 'Privacy Concerns' was selected from three different studies $[18,19,29]$ This construct included five statements. The next construct 'Perceived ease of use' was adopted from Sukhu et al. [17] with four statements. 'Social trust' was picked from Salehan et al. [16], which had three statements. The last construct 'Perceived usefulness/Benefits associated with personal information sharing' was taken from Beldad's study [15], and it had four statements.

The instrument consisted of two sections: Section A of the instrument had six subsections. The participants were requested to respond to the statements on a five-point Likert scale. Section B elicited the participants' demographic information with five questions about the participants' gender, age, marital status, educational qualification, and occupation.

A preliminary draft of the questionnaire was prepared to vet it from the field experts to address any ambiguity or repetition of ideas before sending it to the target audience. The draft was sent to five specialists, including faculty, researchers, and practitioners of information management, to ensure the questionnaire's content validity. The experts looked at it critically and provided their feedback, which was incorporated as per their recommendations, and the questionnaire was finalized. The vetted questionnaire was converted into an online form using Google Docs and was sent to 33 Facebook users. They responded well, and no ambiguity was found in the questionnaire except for some typos corrected immediately. The data received from these 33 pilot testing participants were analyzed by using Software Package for Social Sciences (SPSS) version 22.0. To check the instrument's reliability, Cronbach's Alpha was applied for the calculation of the internal 
consistency of the statements based on pilot data. Cronbach's Alpha value remained between 0.7 to 0.9 . Google Docs based questionnaire was distributed from 20 June to 31 July 2020. The questionnaire link was distributed through Facebook pages and groups, WhatsApp, and e-mails. Follow-up calls and messages through Facebook messenger and WhatsApp messages were also sent. As a result, a total of 407 responses were received from the target population. The responses $(n=407)$ collected for this study were entered into the Statistical Package for Social Sciences (SPSS) version 22.0. This exercise aimed to compile a data file for examination and review before the final data analysis. The seven responses were removed if they had missing and abnormal values.

To check the final instrument's reliability based on the collected data, a Cronbach's Alpha was applied to calculate the internal consistency of the statements. All the constructs showed good reliability values (between 0.7 to 0.9 ). Theoretical hypotheses were tested through SmartPLS-SEM 3.0 (Bonningstedt, Pinneberg, Germany).

\section{Data Analysis}

A total of 400 Pakistani Facebook users responded to the questionnaire with valid responses. The distribution of age groups in Table 2 shows that young people aged between 21 to 30 years participated in this study enthusiastically. In contrast, teenagers did not take much interest in filling out the questionnaire. The possible reason for being the largest age group (21-30 years) would be that this age group takes research seriously. Another reason could be that this age group considered students at the undergrad or graduate level, so they responded well as they might understand the importance of research. Additionally, as students, they were not attending their academic institutions due to COVID-19, so they might have had enough time to respond to this study.

Table 2. Demographic Variables $(n=400)$.

\begin{tabular}{|c|c|c|}
\hline Demographic Variables & $f$ & $\%$ \\
\hline \multicolumn{3}{|l|}{ Age } \\
\hline Up to 20 years & 26 & 6.5 \\
\hline $21-30$ years & 171 & 42.8 \\
\hline $31-40$ years & 99 & 24.8 \\
\hline More than 40 years & 104 & 26.0 \\
\hline \multicolumn{3}{|l|}{ Gender } \\
\hline Male & 258 & 65.2 \\
\hline Female & 138 & 34.8 \\
\hline \multicolumn{3}{|l|}{ Marital Status } \\
\hline Bachelor & 185 & 46.4 \\
\hline Married & 212 & 53.1 \\
\hline Other (Divorced) & 2 & 0.5 \\
\hline \multicolumn{3}{|l|}{ Educational Level } \\
\hline Matric/O-Level & 13 & 3.3 \\
\hline Intermediate/A-Level & 27 & 6.8 \\
\hline $\mathrm{BA} / \mathrm{BSc}$ & 55 & 13.8 \\
\hline $\mathrm{MA} / \mathrm{MSc} / \mathrm{BS}$ & 182 & 45.6 \\
\hline MS/M.Phil. & 92 & 23.1 \\
\hline Ph.D. & 30 & 7.5 \\
\hline \multicolumn{3}{|l|}{ Occupation } \\
\hline Business & 25 & 6.3 \\
\hline Job & 251 & 62.9 \\
\hline Nothing (no business/job) & 22 & 5.5 \\
\hline Study & 101 & 25.3 \\
\hline
\end{tabular}


The educational background distribution revealed that the largest group of participants in this study had an MA/MSc/BS degree. The reason behind this might be that the majority of the respondents belonged to the age group of 21-30 years. In Pakistan, students usually complete their master's degree (after 16 years of education in Pakistan) in the same age group [85]. (Previously, Kanwal et al. [86] also reported that the Pakistani younger generation and most students were SNSs addicts. This could be a reason for the high participation of people having a MA/MSc/BS degree.

Furthermore, in Pakistan, Mphil/MS/Ph.D. degree holders are smaller in number as compared to the MA/MSc/BS degree holders. On the contrary, the smallest group of contributors had a Matric/O-Level education. This might be because the research cannot expect a holder of a 10-years education to participate in a research study, as they do not have enough knowledge and exposure to understand the importance of participation in research studies in the Pakistani context.

The people who were employed in a job made up the largest group of participants in this study. The reason for this might be that they have more opportunities and time to take part in such research activities. On the other hand, unemployed people might not have computing and internet facilities.

\subsection{Analysis of Measurements and Structural Model}

All the study constructs were reflective in nature. The structural equation model was employed using partial least squares (PLS) analysis to assess the measurement and structural model for reflective constructs.

\subsubsection{Estimation of the Outer Measurement Model Reliability}

To investigate the reliability of the constructs, the study adopted the suggestion of Hair et al. [87] in that the reliability of the constructs should be measured in two ways, first by measuring Chronbach's alpha and second by the composite reliability against the threshold value $>0.70$ [87]. Data in Table 3 show that for all constructs, Chronbach's alpha values and the composite reliability values were above the threshold $>0.70$. Therefore, it can be safely concluded that all constructs were reliable.

Table 3. Reliability and Validity Measures.

\begin{tabular}{ccccccc}
\hline Scale & $\begin{array}{c}\text { Composite } \\
\text { Reliability }\end{array}$ & $\begin{array}{c}\text { Cronbach's } \\
\text { Alpha }\end{array}$ & AVE & Rho-A & R-sq. & $\begin{array}{c}\text { Adjusted } \\
\text { R-sq. }\end{array}$ \\
\hline Ease of Use & 0.94 & 0.91 & 0.79 & 0.92 & - & - \\
\hline Perceived Usefulness & 0.89 & 0.83 & 0.67 & 0.83 & 0.01 & 0.09 \\
\hline Privacy Concerns & 0.92 & 0.88 & 0.73 & 0.88 & - & - \\
\hline Trust in Medium & 0.94 & 0.92 & 0.77 & 0.92 & 0.13 & 0.12 \\
\hline Social Trust & 0.87 & 0.78 & 0.69 & 0.80 & 0.17 & 0.17 \\
\hline Self-disclosure & 0.86 & 0.79 & 0.54 & 0.81 & 0.31 & 0.30 \\
\hline
\end{tabular}

\section{Convergent Validity}

The convergent validity of the constructs was measured by the average variance extracted (AVE). AVE measures the average variance shared between the construct and its indicators. AVE's threshold value is $0.5(50 \%)$ or higher [88]. The results in Table 3 confirm that all constructs' convergent validity was above the accepted threshold value, i.e., 0.5 or higher.

\section{Multi Collinearity}

To examine the values of collinearity, variance inflation factor (VIF), the significance of outer weights, and the significance of item loadings were examined [89]. VIF values for all 
items of constructs were between 1-5 and were within the range of threshold value (Table 4). The results in Table 4 further indicate that for all the construct items, outer weights were significant. Secondly, outer loadings for all construct items were higher $(>0.6)$ than the threshold value and were significant.

Table 4. Multi Collinearity.

\begin{tabular}{|c|c|c|c|c|c|}
\hline Constructs & VIF & Outer Weights & $p$ & Item Loadings & $p$ \\
\hline \multicolumn{6}{|c|}{ Perceived Usefulness/Benefits } \\
\hline BENE1 & 1.71 & 0.30 & 0.00 & 0.78 & 0.00 \\
\hline BENE2 & 1.81 & 0.31 & 0.00 & 0.81 & 0.00 \\
\hline BENE3 & 2.13 & 0.28 & 0.00 & 0.82 & 0.00 \\
\hline BENE4 & 2.19 & 0.35 & 0.00 & 0.85 & 0.00 \\
\hline \multicolumn{6}{|c|}{ Perceived Ease of Use } \\
\hline EASE OF USE1 & 3.11 & 0.31 & 0.00 & 0.90 & 0.00 \\
\hline EASE OF USE2 & 3.15 & 0.29 & 0.00 & 0.91 & 0.00 \\
\hline EASE OF USE3 & 2.06 & 0.28 & 0.00 & 0.83 & 0.00 \\
\hline EASE OF USE4 & 3.37 & 0.25 & 0.00 & 0.91 & 0.00 \\
\hline \multicolumn{6}{|c|}{ Privacy Concerns } \\
\hline PRIVACY1 & 1.97 & 0.34 & 0.00 & 0.85 & 0.00 \\
\hline PRIVACY2 & 2.24 & 0.25 & 0.00 & 0.84 & 0.00 \\
\hline PRIVACY3 & 2.49 & 0.23 & 0.00 & 0.87 & 0.00 \\
\hline PRIVACY 4 & 2.18 & 0.30 & 0.00 & 0.85 & 0.00 \\
\hline \multicolumn{6}{|c|}{ Trust in FB } \\
\hline TRUST1 & 3.15 & 0.22 & 0.00 & 0.87 & 0.00 \\
\hline TRUST2 & 3.59 & 0.23 & 0.00 & 0.89 & 0.00 \\
\hline TRUST3 & 3.80 & 0.23 & 0.00 & 0.91 & 0.00 \\
\hline TRUST4 & 3.13 & 0.23 & 0.00 & 0.89 & 0.00 \\
\hline TRUST5 & 1.96 & 0.24 & 0.00 & 0.81 & 0.00 \\
\hline \multicolumn{6}{|c|}{ Social Trust } \\
\hline SOCIALTRUST1 & 1.43 & 0.44 & 0.00 & 0.82 & 0.00 \\
\hline SOCIALTRUST2 & 1.81 & 0.39 & 0.00 & 0.85 & 0.00 \\
\hline SOCIALTRUST3 & 1.67 & 0.38 & 0.00 & 0.82 & 0.00 \\
\hline \multicolumn{6}{|c|}{ Self-Disclosure/PISB } \\
\hline PISB1 & 1.42 & 0.24 & 0.00 & 0.68 & 0.00 \\
\hline PISB2 & 1.37 & 0.25 & 0.00 & 0.65 & 0.00 \\
\hline PISB3 & 1.93 & 0.29 & 0.00 & 0.81 & 0.00 \\
\hline PISB4 & 1.83 & 0.27 & 0.00 & 0.77 & 0.00 \\
\hline PISB5 & 1.41 & 0.31 & 0.00 & 0.74 & 0.00 \\
\hline
\end{tabular}

Discriminant Validity

If the average variance shared between the construct and its individual indicators was higher than 0.5, the next step was to measure the constructs' distinctiveness. Henseler et al. [90] suggested applying the heterotrait-monotrait ratio of correlations (HTMT). Hair Jr. [88] encouraged application of HTMT 0.85 cutoff scores to interpret the HTMT results to verify the distinctiveness of the constructs. All the constructs' values were lower than 0.85 , which proved that all constructs were distinctive in nature (Table 5). 
Table 5. Discriminant Validity (HTMT).

\begin{tabular}{|c|c|c|c|c|c|c|}
\hline & Benefits & Ease of Use & Self-Disclosure & Privacy Concerns & Social Trust & Trust in Medium \\
\hline \multicolumn{7}{|l|}{$\begin{array}{c}\text { Perceived } \\
\text { Usefulness/Benefits }\end{array}$} \\
\hline Perceived Ease of Use & 0.34 & & & & & \\
\hline Self-disclosure & 0.66 & 0.28 & & & & \\
\hline Privacy Concerns & 0.13 & 0.17 & 0.09 & & & \\
\hline Social Trust & 0.36 & 0.44 & 0.37 & 0.12 & & \\
\hline Trust in Medium & 0.33 & 0.44 & 0.25 & 0.19 & 0.48 & \\
\hline
\end{tabular}

\subsubsection{Confirmatory Factor Analysis}

For confirmatory factor analysis, PLS-SEM was applied as it is suitable to measure complex models with endogenous and exogenous constructs and indicators. Furthermore, the sample size was reasonably large for PLS analysis, as Hair et al. [91] suggested. PLSSEM analysis suggested a good model fit $(\mathrm{SRMR}=0.097, \mathrm{NFI}=0.806)$ as the SRMR value was less than 0.10, and the NFI value was close to 1 [92]. Figure 2 revealed that the item loadings were within the threshold value i.e., 0.5 as recommended by Awang [93], and $\mathrm{t}$ values (depicted in the constructs' relationship paths) and $p$ values were all accepted and significant. Furthermore, Table 3 depicts that the composite reliability values for all constructs were more than 0.7 , the average variance extracted values confirmed the convergent reliability i.e., $>0.5$ [88], and Rho_A reliability coefficients were above 0.7 , which was an acceptable range [94]. The discriminant validity was measured through HTMT, and the values for all constructs met the criteria of HTMT 0.85 cutoff scores suggested by Hair Jr. [88] (Table 5).

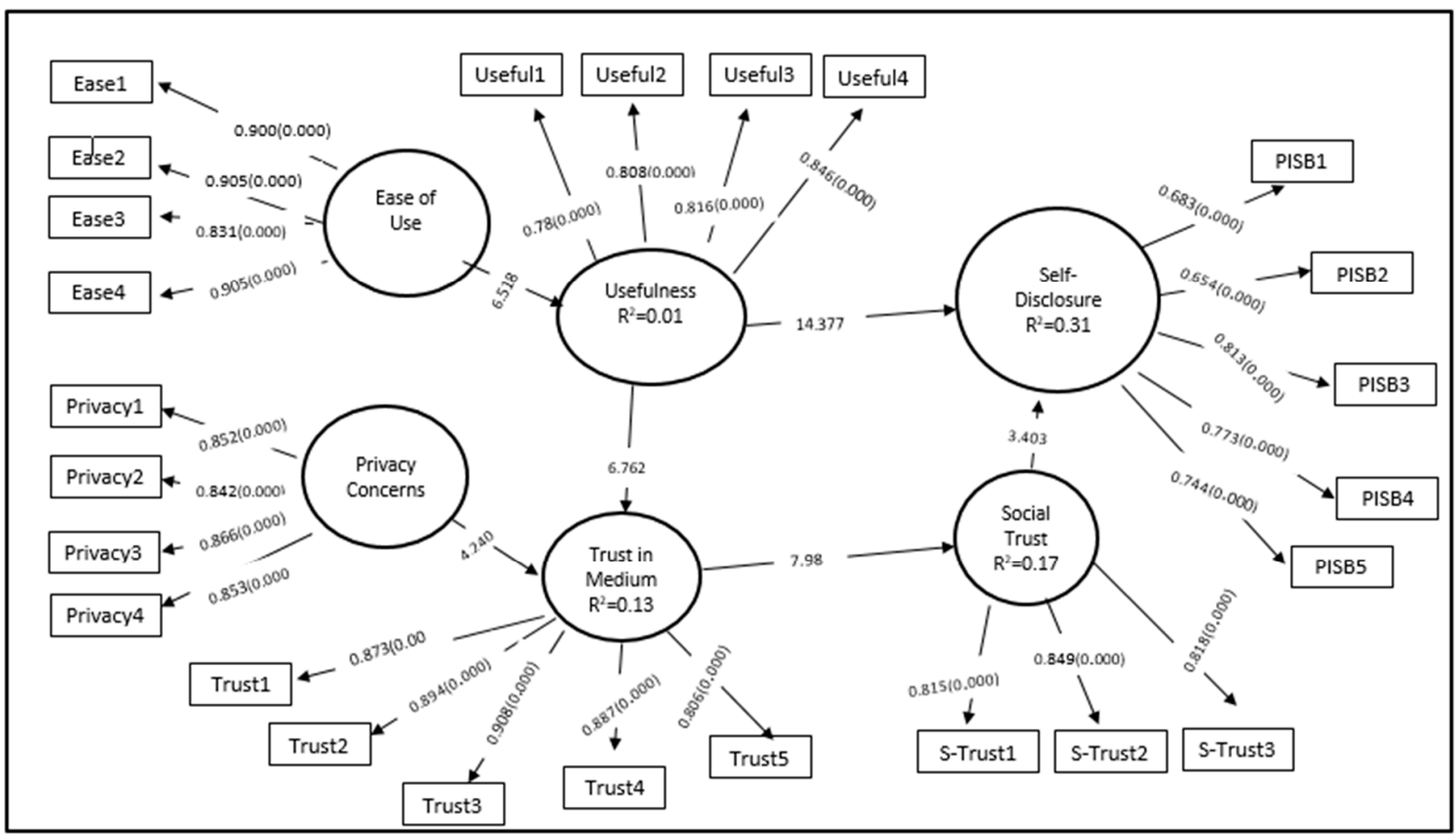

Figure 2. Confirmatory Factor Analysis and Structural Model of Self-Disclosure Behavior. 


\subsubsection{Estimation of the Inner Measurement Model} Estimation of Path Coefficients $(\beta)$ and T-Statistics

The path coefficients were estimated, and $\beta$ denoted the expected variation in the dependent construct for a unit variation in the independent construct(s). The bootstrapping procedure was adopted to evaluate the significance of the hypothesis. To test the significance of the path coefficient and T-statistics values, a bootstrapping procedure using 5000 subsamples with no significant changes was carried out for this study, and the results are presented in Table 6.

Table 6. Path Analysis.

\begin{tabular}{cccccc}
\hline Hypotheses & & Path Coefficients $\boldsymbol{\beta}$ & t-Statistics & $p$-Value & Remarks \\
\hline H1 & Perceived Ease of Use > Perceived Usefulness & 0.30 & 6.16 & 0.00 & Accepted \\
\hline H2 & Perceived usefulness > Trust in Medium & 0.31 & 6.76 & 0.00 & Accepted \\
\hline H3 & Privacy Concerns > Trust in Medium & -0.21 & 4.24 & 0.00 & Accepted \\
\hline H4 & Trust in Medium > Social Trust & 0.41 & 7.99 & 0.00 & Accepted \\
\hline H5 & Perceived Usefulness > Self-disclosure & 0.49 & 14.38 & 0.00 & Accepted \\
\hline H6 & Social Trust > Self-disclosure & 0.14 & 3.40 & 0.00 & Accepted \\
\hline
\end{tabular}

Data in Table 6 show that all hypotheses were accepted at $p<0.01$. It was proved that individuals who find Facebook a medium that is easy to use agreed with the benefits of personal information sharing $(B=0.30, t=6.16, p<0.00)$. Similarly, the people who agreed that personal information sharing behavior had its benefits considered Facebook a trustworthy medium $(\mathrm{B}=0.31, \mathrm{t}=6.76, p<0.00)$. The data in Table 6 show the negative impact of privacy concerns on Facebook's trust $(\mathrm{B}=-0.20, \mathrm{t}=4.24, p<0.00)$.

However, it was confirmed that trust in the medium (Facebook) had a significant positive impact on developing social trust $(\mathrm{B}=0.41, \mathrm{t}=7.99, p<0.00)$. Further, social trust had a significant positive impact on personal information sharing behavior $(\mathrm{B}=0.14$, $\mathrm{t}=3.40, p<0.001$ ).

Furthermore, a strong impact of the perceived benefits associated with personal information sharing practices on personal information sharing behavior was also witnessed $(\mathrm{B}=0.49, \mathrm{t}=14.38, p<0.00)$. The graphical presentation of path analysis is referred to in Figure 3.

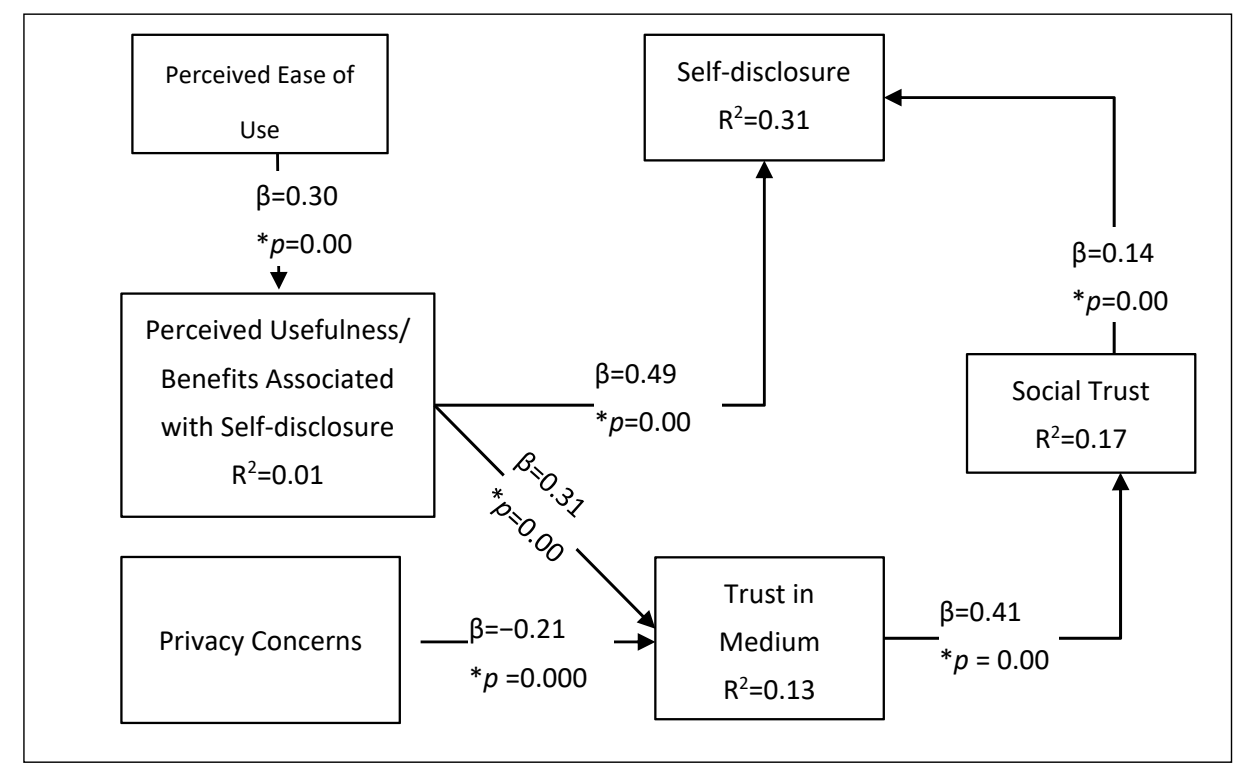

Figure 3. Self-disclosure Model, Note: * Significant Path. 


\subsubsection{Model Prediction}

To examine the predictability power of the model, PLSpredict was applied. According to Shmueli et al. [95], the precondition to applying this test is that Q2 predict for all the dependent constructs' indicators should be more than 0 . The MV prediction summary showed that PLS-SEM Q2 $2_{\text {predict }}$ for all the dependent constructs' indicators was above 0 . Thus, on the second step, error histograms for the indicators were observed to find out if the distribution was symmetrical, PLS-SEM error plots were not normally distributed, and this was confirmed from the values of Skewness, Kurtosis, and Shapiro-Wilk test as well (Table 7).

Table 7. Distribution of PLS-SEM Prediction Errors.

\begin{tabular}{ccccc}
\hline Variables & $\mathbf{Z}_{\text {Skewness }}$ & $\mathbf{Z}_{\text {Kurtosis }}$ & Shapiro-Wilk (Statistics) & $p$-Value \\
\hline $\begin{array}{c}\text { Perceived Usefulness } \\
\text { Benefits }\end{array}$ & -15.95 & 2.93 & 0.97 & 0.00 \\
\hline Trust in Medium & -0.6 & -7.39 & 1.00 & 0.00 \\
\hline Social Trust & -12.92 & 3.20 & 0.97 & 0.00 \\
\hline Self-Disclosure & 8.35 & -7.20 & 0.98 & 0.00 \\
\hline
\end{tabular}

Therefore, it was decided to review the difference between PLS-SEM MAE and LM MAE values instead of RMSE values as per the guidelines of [95]. Since the minority of the dependent construct's indicators produced lower PLS-SEM prediction errors than the Naive LM benchmark (Table 8), it could be concluded that the model had a low predictive power.

Table 8. PLSpredict Assessment of Manifest Variables.

\begin{tabular}{ccccc}
\hline Indicators & \multicolumn{2}{c}{ PLS-SEM } & LM & \\
\hline & Mae & $\mathbf{Q}^{2}$ Predict & Mae & Pls-Sem -Lm MAE \\
\hline BENE1 & 0.86 & 0.04 & 0.87 & -0.01 \\
\hline BENE2 & 0.83 & 0.07 & 0.84 & -0.01 \\
\hline BENE3 & 0.86 & 0.04 & 0.84 & 0.02 \\
\hline BENE4 & 0.84 & 0.08 & 0.85 & -0.01 \\
\hline TRUST1 & 0.83 & 0.07 & 0.80 & 0.03 \\
\hline TRUST2 & 0.77 & 0.10 & 0.75 & 0.02 \\
\hline TRUST3 & 0.80 & 0.08 & 0.78 & 0.03 \\
\hline TRUST4 & 0.77 & 0.08 & 0.74 & 0.03 \\
\hline TRUST5 & 0.80 & 0.06 & 0.77 & 0.02 \\
\hline SOCIALTRUST1 & 0.82 & 0.02 & 0.79 & 0.03 \\
\hline SOCIALTRUST2 & 0.71 & 0.01 & 0.68 & 0.03 \\
\hline SOCIALTRUST3 & 0.74 & 0.01 & 0.66 & 0.08 \\
\hline PISB1 & 1.23 & 0.04 & 1.18 & 0.10 \\
\hline PISB2 & 1.32 & 0.01 & 1.31 & 0.01 \\
\hline PISB3 & 1.17 & 0.03 & 1.17 & -0.00 \\
\hline PISB4 & 1.02 & 0.02 & 1.04 & 0.02 \\
\hline PISB5 & 1.14 & 0.04 & 1.12 & \\
\hline
\end{tabular}

\section{Findings and Discussion}

Social media offers several opportunities to share and exchange personal information, i.e., opinions, pictures, videos. People use social media for self-disclosure [96]. In particular, 
Facebook is the most popular social media platform. Self-disclosure relieves loneliness [22], strengthens relational closeness [97], expands the social network [98], develops social capital [20], increases the feeling of connectedness [21], and improves subjective wellbeing [23,24]. A sense of self-expression [99] and a feeling of familiarity with oneself [100] are some other motives of self-disclosure. Individuals who express their thoughts, posts, hopes, and hobbies would essentially obtain more attention from friends and family members [86]. Thus, it can be concluded that self-disclosure has several associated benefits, i.e., it satisfies individuals' self-esteem, helps develop social capital, maintains relationships with friends and family members, and develops new relations.

This study provides several interesting findings in the field of information sharing behavior and self-disclosure. It highlights the antecedents of self-disclosure based on the technology acceptance model (TAM). The two main constructs of TAM were found to be correlated. It is confirmed from the findings of the current study that if technology and information systems cause no or little physical and mental exertion, people consider that technology or information system is useful. Earlier, Cho and Sagynov [72] confirmed that online customers find shopping more beneficial if they can easily navigate through the online store. Similarly, Amin et al. [65] suggested that mobile marketers should make users' work easier if they intend to increase technology's perceived usefulness and adoption.

The research discloses that the perceived usefulness/benefits of self-disclosure and the Facebook community's trust significantly and directly impact personal information sharing behavior. If individuals are aware of personal information sharing benefits, they will share personal information more frequently. Thus, this study declared that the benefits of sharing personal information behavior are the most prominent antecedent among other antecedents under study. The people of Pakistan post their personal information considering that Facebook increases their popularity by sharing photos, ideas, activities, etc. This way, they present themselves before the members of their social network. Past studies also reported the same results as this study. Beldad [15] revealed in his study, which was carried out in the Netherlands, that information sharing benefits were a strong predictor of young users' decision to share personal information on Facebook. Similarly, the results of research by Kim and Kim [73] conducted at Midwestern University, USA, showed that the benefits of personal information sharing on the web convinced users to publish their personal information. Considering the results obtained, we can conclude that the higher the benefits of self-disclosure that individuals perceive, the higher their volume of personal information sharing will be.

Similarly, people will share personal information more frequently if they trust those who have access to that information. Earlier studies have provided similar results to the current study. Salehan et al. [16] uncovered that social trust is positively associated with personal information sharing behavior. Likewise, Hong and Hashim [30] discovered in their study conducted in Northern Malaysia that social trust represented one of the positive features of Facebook relationships. Additionally, Dwyer et al. [81] reported that Facebook members were trustworthy, so they were more willing to include personal information in their profiles.

Furthermore, social trust is an outcome of trust in the medium. The trust in the medium develops the trust in the community who is using that medium of information. The available literature discusses the impact of social norms on an individual's trust in a medium, but little is known about the impact of trust in a medium on the trust of the community of that particular medium [80], which is measured empirically in the current study. However, there is a need to test this impact further on different mediums and in different contexts.

Whereas privacy concerns are negatively associated with trust in the medium. If individuals have fewer privacy concerns, they will have more trust in the medium. Some previous studies also reported the same results. Higher privacy concerns are associated with weaker intentions to utilize online services [78]. As individuals' belief that accessing social networking sites over the internet is secure develops trust in the medium [79]. 
Likewise, Paramarta et al. [32] concluded that control over privacy protection positively impacted trust in social media among Indonesian people. Thus, the current study concludes that there was a negative impact of privacy concerns on trust in mediums, leading to self-disclosure through social trust.

\section{Conclusions}

The study concludes that self-disclosure behavior is dependent on multiple factors, i.e., individuals' perceptions about the usefulness of personal information sharing, trust in the community to whom personal information is shared, trust in the medium, i.e., Facebook will keep its promises and will use personal information fairly. Although individuals' perceived ease of use does not impact self-disclosure directly, it does, however, help them to understand the potential benefits of self-disclosure. Similarly, the people who consider personal information sharing riskier will have less trust in the medium and its community members, and, as a result, they will share personal information on Facebook less frequently.

It can be concluded that the perceived usefulness of self-disclosure practices and social trust impact directly whereas, perceived ease of use and privacy concerns indirectly impact the personal information sharing behavior. Likewise, trust in a medium and a community plays a mediating role. Furthermore, the impact of two independent variables borrowed from TAM proved stronger predictors of self-disclosure behavior, as compared to the other predictors. The study supports the theory of TAM.

\section{Theoretical Contributions and Policy Implications}

Theoretically, the study strengthens the literature on the use of SNSs and self-disclosure from developing countries. Furthermore, a handful of studies on the topic are based on the students' data only, and little is known about the general public's self-disclosure behavior. The current study somehow tries to bridge this gap in the literature. Additionally, the study extends TAM by including mediating variables, particularly by exploring the impact of "trust in the medium" on "social trust" that has rarely been explored previously.

The study offers several policy implications:

1. Ease of technology use positively impacts the individuals' perceived usefulness of a medium/technology-related practice. It poses two types of implications; first, the SNSs administrators should try to develop user-friendly platforms for communication. Secondly, the government should devise policies to train individuals to use the technology effectively, and these policies should be implemented with the help of academic institutions (for students), employers (for employees), public libraries, and community centers through organizing training programs (for the general public). These training courses may be designed for different levels i.e., beginners and intermediate. The training contents may cover basic use to expert use of technology and social media for personal, professional, and economic benefits. In this way, individuals may find these kinds of mediums easy to use and may actively share personal information that will ultimately give them the associated benefits, i.e., social capital development, connectedness, self-esteem, etc.

2. It is also found that individuals with better awareness about the benefits of selfdisclosure practice more frequently. Therefore, it is suggested that Facebook users should be guided about self-disclosure and its advantages. Particularly, psychiatrists and educators who want individuals to disclose their personal information with the purpose to connect them with others and reduce loneliness should consider that individuals will adopt this behavior if they consider it useful. Therefore, the potential benefits of self-disclosure must be communicated to the individuals by psychiatrists and educators.

3. In the current era, when SNSs have incorporated advanced privacy measures, individuals still show privacy concerns, and these negatively impact the trust in the medium of communication. Whereas trust in the medium has an indirect positive impact on self-disclosure behavior. As a matter of policy, SNSs providers should 
implement privacy policies and enhance an individual's control over their personal information [74]. Furthermore, users must be trained to manage their privacy settings, which will reduce their privacy concerns. In this way, individuals will have more trust in the medium that mitigates personal information sharing behavior. Similarly, social networking sites, especially Facebook, should attract baby boomers and generation $X$ to join and use social media network sites, as they use this type of platform the least.

4. Social trust triggers self-disclosure; SNSs administrators should take such measures that enhance individuals' trust in the SNSs community. For example, the fair use of information policy should be encouraged through a quick response to the users' complaints. SNSs users may be guided on how and to whom they may contact if they find other members misusing their personal information. The national cyber-crime department should give cyber-crime awareness through seminars and training in liaison with academic institutions and public libraries.

These types of studies are conducted to potentially modify the users' information sharing behavior by educating them through workshops, conferences, seminars, discussions, etc, as well as, help to address the negatively impacting variables, if found, for effective social networking sites' use.

\section{Limitations and Future Directions}

Although this study has provided us with some useful implications, some limitations can be addressed through future research. The study is based on a convenient sampling technique; therefore, the results cannot be generalized. Since this study was limited to the independent and mediating variables, a similar study could be carried out using other possible factors that potentially impact personal information sharing behavior as a moderator. Relating to the sample, the only required criterion to fill out the online form was that the respondents should be Pakistani Facebook users. However, the frequency of Facebook use was not measured, which is also a limitation of the study. Keeping in view the limitation of this study to a country-specific population, the legitimacy regarding the influence of various demographics and cultures could be varied. To prove it, a study could be conducted in the future on an international level to examine if the variables produce similar results. Finally, the world of technology is rapidly changing day-by-day. While this study may have recognized some of the predictors of personal information sharing behavior, it does not mean that our suggested model can completely reflect the actual situations in the future.

Author Contributions: A.S.: Conceptualization; Methodology, Investigation, Writing—Original Draft. S.H.S.: Conceptualization, Methodology, Formal Analysis, Writing - Original Draft, WritingReview \& Editing, Project administration. S.A.: Writing-Review \& Editing, K.M.: Conceptualization; Supervision. All authors have read and agreed to the published version of the manuscript.

Funding: This research received no external funding to conduct the research.

Institutional Review Board Statement: For ensuring ethical considerations, the study was reviewed and approved by the Department of Information Management, University of the Punjab, Lahore.

Informed Consent Statement: Informed consent was obtained from all the subjects involved in the study.

Data Availability Statement: The data presented in this study are available on request from the corresponding author.

Acknowledgments: The authors would like to acknowledge the support of Prince Sultan University, Saudi Arabia for paying the Article Processing Charges (APC) of this publication.

Ethics Statement: The respondents were ensured that their identity will not be disclosed, and the data will be used for research purposes only.

Conflicts of Interest: The authors declare no conflict of interest. 


\section{Appendix A}

Table A1. Research Instrument.

\begin{tabular}{|c|c|c|}
\hline S. No & Statements & Adapted after \\
\hline 1 & \multicolumn{2}{|l|}{ Self-disclosure Behavior } \\
\hline 2 & $\begin{array}{l}\text { I share my personal information (such as real name, current town, sexual orientation, } \\
\text { education, employment, and so on) on my Facebook page }\end{array}$ & [16] \\
\hline 3 & $\begin{array}{l}\text { I have my contact information (such as email, cell phone number, address, and so on) on } \\
\text { my Facebook page }\end{array}$ & [16] \\
\hline 4 & I share my personal pictures on my Facebook page & [16] \\
\hline 5 & I share my personal videos on my Facebook page & [16] \\
\hline 6 & I share my ideas, opinions, and recommendations through my Facebook page & [16] \\
\hline \multicolumn{3}{|c|}{ Perceived Usefulness of Self-disclosure } \\
\hline 1 & Posting photos of myself on Facebook increases my popularity & [15] \\
\hline 2 & $\begin{array}{l}\text { Posting my thoughts and opinions on certain issues makes me an interesting person } \\
\text { on Facebook }\end{array}$ & [15] \\
\hline 3 & Posting details about my activities allows me to inform many members of Facebook & [15] \\
\hline 4 & $\begin{array}{l}\text { Posting information about myself on Facebook is a way to represent myself to many } \\
\text { members of my network }\end{array}$ & [15] \\
\hline \multicolumn{3}{|c|}{ Privacy Concerns } \\
\hline 1 & Facebook could cause serious privacy problems & [18] \\
\hline 2 & I am concerned about threats to my personal privacy & [18] \\
\hline 3 & $\begin{array}{l}\text { I am concerned that someone can find information about me on Facebook that I want to } \\
\text { keep private }\end{array}$ & [18] \\
\hline 4 & I am concerned that the information I posted on Facebook could be misused & [19] \\
\hline 5 & I am concerned about identity theft on the Facebook & [29] \\
\hline \multicolumn{3}{|c|}{ Trust in Facebook } \\
\hline 1 & I believe Facebook is honest to its users & [17] \\
\hline 2 & I believe Facebook acts sincerely in dealing with users & [17] \\
\hline 3 & I believe Facebook is truthful in its dealing with users & [17] \\
\hline 4 & I believe Facebook would keep its commitments & [17] \\
\hline 5 & I believe Facebook is genuine & [17] \\
\hline \multicolumn{3}{|c|}{ Social Trust } \\
\hline 1 & In general, my Facebook friends can be trusted & [16] \\
\hline 2 & My Facebook friends try to be fair & [16] \\
\hline 3 & My Facebook friends try to be helpful & [16] \\
\hline \multicolumn{3}{|c|}{ Perceived Ease of Use } \\
\hline 1 & Learning to use Facebook was easy for me & [17] \\
\hline 2 & My interaction with Facebook is clear and understandable & [17] \\
\hline 3 & It is easy for me to become skillful at using Facebook & [17] \\
\hline 4 & I find Facebook easy to use & [17] \\
\hline
\end{tabular}




\section{References}

1. Leiner, B.M.; Cerf, V.G.; Clark, D.D.; Kahn, R.; Kleinrock, L.; Lynch, D.; Wolff, S. Histories of the Internet: A Brief History of the Internet. Available online: https://www.usit.uio.no/om/organisasjon/sst/stab/ansatte/bness/tilkoplet/web/7/src/brianleiner-a-brief-history-of-the-internet.pdf (accessed on 10 September 2020).

2. Edosomwan, S.; Prakasan, S.K.; Kouame, D.; Watson, J.; Seymour, T. The history of social media and its impact on business. J. Appl. Manag. Entrep. 2011, 16, 79-91.

3. Facebook: Our History. Available online: https://about.fb.com/company-info/ (accessed on 12 February 2020).

4. Kemp, S. Digital 2019: Global Internet Use Accelerates. 2019. Available online: https://wearesocial.com/global-digital-report-20 19 (accessed on 14 February 2020).

5. AlQadheeb, B.E.; Alsalloum, O.I. Self-disclosure in social networking sites in Saudi Arabia. Int. J. Bus. Manag. 2018, 13, 96-115. [CrossRef]

6. Global Web Index. Social Media Engagement. 2019. Available online: https://www.globalwebindex.com/hubfs/Downloads/20 19\%20Q1\%20Social\%20Flagship\%20Report.pdf (accessed on 12 March 2020).

7. Statista. Social Media \& User-Generated Content. Available online: https://www.statista.com/statistics/264810/number-ofmonthly-active-facebook-users-worldwide/ (accessed on 22 February 2020).

8. Zephoria. The Top 20 Valuable Facebook Statistics-Updated June 2020. Available online: https:/ / zephoria.com/top-15-valuablefacebook-statistics / (accessed on 22 March 2020).

9. Nie, J.; Li, W.; Wang, P.; Wang, X.; Wang, Y.; Lei, L. Adolescent type D personality and social networking sites addiction: A moderated mediation model of restorative outcomes and affective relationships. Psychiatry Res. 2019, 271, 96-104. [CrossRef] [PubMed]

10. Meshi, D.; Mamerow, L.; Kirilina, E.; Morawetz, C.; Margulies, D.S.; Heekeren, H.R. Sharing self-related information is associated with intrinsic functional connectivity of cortical midline brain regions. Sci. Rep. 2016, 6, 1-11. [CrossRef] [PubMed]

11. Archer, J.L. The self in social psychology. In Self-Disclosure; Wegner, D., Vallacher, R., Eds.; Oxford University Press: London, UK, 1980; pp. 183-204.

12. Dinev, T.; Hart, P. An extended privacy calculus model for e-commerce transactions. Inf. Syst. Res. 2006, 17, 61-80. [CrossRef]

13. Morosan, C.; DeFranco, A. Disclosing personal information via hotel apps: A privacy calculus perspective. Int. J. Hosp. Manag. 2015, 47, 120-130. [CrossRef]

14. Cheung, C.; Lee, Z.W.; Chan, T.K. Self-disclosure in social networking sites. Internet Res. 2015, 25, 279-299. [CrossRef]

15. Beldad, A.D. Sharing to be sociable, posting to be popular: Factors influencing non-static personal information disclosure on Facebook among young Dutch users. Int. J. Web Based Communities 2015, 11, 357-374. [CrossRef]

16. Salehan, M.; Kim, D.J.; Koo, C. A study of the effect of social trust, trust in social networking services, and sharing attitude, on two dimensions of personal information sharing behavior. J. Supercomput. 2018, 74, 3596-3619. [CrossRef]

17. Sukhu, A.; Zhang, T.; Bilgihan, A. Factors influencing information-sharing behaviors in social networking sites. Serv. Mark. Q. 2015, 36, 317-334. [CrossRef]

18. Beuker, S. Privacy Paradox: Factors Influencing Disclosure of Personal Information. Master's Thesis, University of Twente, Enschede, The Netherlands, 2016.

19. Salehan, M.; Kashipaz, S.M.M.; Xu, C. Information sharing on social networking websites: Antecedents and consequences of trust. In Proceedings of the Nineteenth Americas Conference on Information Systems, Chicago, IL, USA, 15-17 August 2013; pp. 1-12.

20. Liu, D.; Brown, B.B. Self-disclosure on social networking sites, positive feedback, and social capital among Chinese college students. Comput. Hum. Behav. 2014, 38, 213-219. [CrossRef]

21. Grieve, R.; Indian, M.; Witteveen, K.; Tolan, G.A.; Marrington, J. Face-to-face or Facebook: Can social connectedness be derived online? Comput. Hum. Behav. 2013, 29, 604-609. [CrossRef]

22. Lee, K.T.; Noh, M.J.; Koo, D.M. Lonely people are no longer lonely on social networking sites: The mediating role of self-disclosure and social support. Cyberpsychology Behav. Soc. Netw. 2013, 16, 413-418. [CrossRef] [PubMed]

23. Lee, G.; Lee, J.; Kwon, S. Use of social-networking sites and subjective well-being: A study in South Korea. Cyberpsychology Behav. Soc. Netw. 2011, 14, 151-155. [CrossRef]

24. Luo, M.; Hancock, J.T. Self-disclosure and social media: Motivations, mechanisms and psychological well-being. Curr. Opin. Psychol. 2020, 31, 110-115. [CrossRef]

25. Nabity-Grover, T.; Cheung, C.M.; Thatcher, J.B. Inside out and outside in: How the COVID-19 pandemic affects self-disclosure on social media. Int. J. Inf. Manag. 2020, 55, 102188. [CrossRef]

26. Chen, H. Antecedents of positive self-disclosure online: An empirical study of US college students' Facebook usage. Psychol. Res. Behav. Manag. 2017, 10, 147. [CrossRef]

27. Harden, G.; Al Beayeyz, A.; Visinescu, L. Concerning SNS Use: How do issues of privacy and trust concern users? In Proceedings of the AMCIS 2012, Seattle, WA, USA, 9-11 August 2012; p. 4. Available online: https:/ / aisel.aisnet.org/amcis2012/proceedings / SocialIssues / 4/ (accessed on 16 April 2020).

28. Ozkan, E. Why do consumers behave differently in personal information disclosure and self-disclosure? The role of personality traits and privacy concern. Alphanumeric J. 2018, 6, 257-276. 
29. Kalmer, N.P.; Schultheiss, R. Self-Disclosure on Facebook: Social Network Site Privacy and Personal Information Disclosure of Germans and Norwegians: A Cross-Cultural Comparison. Master's Thesis. 2018. Available online: https://www.diva-portal. org/smash/record.jsf?pid=diva2\%3A1221768\&dswid=-3599 (accessed on 16 April 2020).

30. Hong, O.S.; Hashim, I.H.M. Social trust over Facebook among Malaysian university students. In Proceedings of the Social Sciences Postgraduate International Seminar (SSPIS), Penang, Malaysia, 15 December 2016; pp. 193-199.

31. Zhang, R.; Fu, J.S. Privacy management and self-disclosure on social network sites: The moderating effects of stress and gender. J. Comput. Mediat. Commun. 2020, 25, 236-251. [CrossRef]

32. Paramarta, V.; Jihad, M.; Dharma, A.; Hapsari, I.C.; Sandhyaduhita, P.I.; Hidayanto, A.N. Impact of user awareness, trust, and privacy concerns on sharing personal information on social media: Facebook, Twitter, and Instagram. In Proceedings of the 2018 International Conference on Advanced Computer Science and Information Systems (ICACSIS), Yogyakarta, Indonesia, 27-28 October 2018; pp. 271-276.

33. Moura, I.V.; De Almeida, L.B.; Da Silva, W.V.; Da Veiga, C.P.; Costa, F. Predictor factors of intention to use technological resources: A multigroup study about the approach of Technology Acceptance Model. Sage Open 2020, 10, 2158244020967942. [CrossRef]

34. Ignatius, E.; Kokkonen, M. Factors contributing to verbal self-disclosure. Nord. Psychol. 2007, 59, 362-391. [CrossRef]

35. Forgas, J.P. Affective influences on self-disclosure: Mood effects on the intimacy and reciprocity of disclosing personal information. J. Personal. Soc. Psychol. 2011, 100, 449-461. [CrossRef] [PubMed]

36. Pearce, W.B.; Sharp, S.M. Self-disclosing communication. J. Commun. 1973, 23, 409-425. [CrossRef] [PubMed]

37. Bazarova, N.N.; Choi, Y.H. Self-disclosure in social media: Extending the functional approach to disclosure motivations and characteristics on social network sites. J. Commun. 2014, 64, 635-657. [CrossRef]

38. Rains, S.A.; Brunner, S.R.; Oman, K. Self-disclosure and new communication technologies: The implications of receiving superficial self-disclosures from friends. J. Soc. Pers. Relatsh. 2016, 33, 42-61. [CrossRef]

39. Ball, A.L.; Ramim, M.M.; Levy, Y. Examining users' personal information sharing awareness, habits, and practices in social networking sites and e-learning systems. Online J. Appl. Knowl. Manag. 2015, 3, 180-207.

40. Koohikamali, M.; Sidorova, A. Information re-sharing on social network sites in the age of fake news. Inf. Sci. Int. J. Emerg. Transdiscipl. 2017, 20, 215-235. [CrossRef]

41. Wheeless, L.R.; Grotz, J. Conceptualization and measurement of reported selfdisclosure. Hum. Commun. Res. 1976, 2, 338-346. [CrossRef]

42. Yu, J.; Hu, P.J.H.; Cheng, T.H. Role of affect in self-disclosure on social network websites: A test of two competing models. J. Manag. Inf. Syst. 2015, 32, 239-277. [CrossRef]

43. Zlatolas, L.N.; Welzer, T.; Hericko, M.; Holbl, M. Privacy antecedents for SNS self-disclosure: The case of Facebook. Comput. Hum. Behav. 2015, 45, 158-167. [CrossRef]

44. Davis, F.D. Perceived usefulness, perceived ease of use, and user acceptance of information technology. Mis Q. 1989, 13, 319-340. [CrossRef]

45. Venkatesh, V. Determinants of perceived ease of use: Integrating perceived behavioral control, computer anxiety and enjoyment into the technology acceptance model. Inf. Syst. Res. 2000, 11, 342-365. [CrossRef]

46. Burton-Jones, A.; Hubona, G.S. Individual differences and usage behaviour: Revisiting a technology acceptance model assumption. Database Adv. Inf. Syst. 2005, 36, 58-77. [CrossRef]

47. Chinje, N.; Chinomona, R. The influence of trust and ease of use of social media platforms on South Africa's generation Y social media use intention and information sharing. In Social Media Marketing; Palgrave Macmillan: Singapore, 2018 ; pp. 93-112.

48. Puspitasari, F.I.; Soebandhi, S.; Subagyo, D.H.; Nugroho, A. Altruism and egoism in e-WOM: The moderating effect of Facebook perceived ease of use. In Proceedings of the 2019 International Seminar on Application for Technology of Information and Communication (iSemantic), Semarang, Indonesia, 21-22 September 2019; pp. 536-541.

49. Pitafi, A.H.; Kanwal, S.; Khan, A.N. Effects of perceived ease of use on SNSs-addiction through psychological dependence, habit: The moderating role of perceived usefulness. Int. J. Bus. Inf. Syst. 2020, 33, 383-407. [CrossRef]

50. Zhou, J. Factors influencing people's personal information disclosure behaviors in online health communities: A pilot study. Asia Pac. J. Public Health 2018, 30, 286-295. [CrossRef] [PubMed]

51. Mican, D.; Sitar-Tăut, D.A.; Moisescu, O.I. Perceived usefulness: A silver bullet to assure user data availability for online recommendation systems. Decis. Support Syst. 2020, 139, 113420. [CrossRef]

52. McKnight, D.H.; Lankton, N.; Tripp, J. Social networking information disclosure and continuance intention: A disconnect. In Proceedings of the 2011 44th Hawaii International Conference on System Sciences, Kauai, HI, USA, 4-7 January 2011; pp. 1-10.

53. Altman, I. Privacy regulation: Culturally universal or culturally specific? J. Soc. Issues 1977, 33, 66-84. [CrossRef]

54. Xu, H.; Dinev, T.; Smith, J.; Hart, P. Information privacy concerns: Linking individual perceptions with institutional privacy assurances. J. Assoc. Inf. Syst. 2011, 12, 798-824. [CrossRef]

55. Gruzd, A.; Hernández-García, Á. Privacy concerns and self-disclosure in private and public uses of social media. Cyberpsychol. Behav. Soc. Netw. 2018, 21, 418-428. [CrossRef]

56. Nepal, S.; Sherchan, W.; Paris, C. Building trust communities using social trust. In International Conference on User Modeling, Adaptation, and Personalization; Springer: Berlin/Heidelberg, Germany, 2012; pp. 243-255.

57. Zucker, L.G. Production of trust: Institutional sources of economic structure, 1840-1920. Res. Organ. Behav. 1986, 8, 53-111. 
58. Jevons, C.; Gabbott, M. Trust, brand equity and brand reality in internet business relationships: An interdisciplinary approach. J. Mark. Manag. 2010, 16, 619-634. [CrossRef]

59. Hsiao, K.L.; Lin, J.C.C.; Wang, X.Y.; Lu, H.P.; Yu, H. Antecedents and consequences of trust in online product recommendations: An empirical study in social shopping. Online Inf. Rev. 2010, 34, 935-953. [CrossRef]

60. Wu, J.J.; Chang, Y.S. Effect of transaction trust on e-commerce relationships between travel agencies. Tour. Manag. 2006, 27, 1253-1261. [CrossRef]

61. Ganzha, M.; Paprzycki, M.; Lirkov, I. Trust management in an agent-based grid resource brokering system-preliminary considerations. In AIP Conference Proceedings; American Institute of Physics: City of University Park, TX, USA, October 2007; Volume 946, pp. 35-46.

62. Chang, C.W.; Heo, J. Visiting theories that predict college students' self-disclosure on Facebook. Comput. Hum. Behav. 2014, 30, 79-86. [CrossRef]

63. Koranteng, F.N.; Wiafe, I.; Katsriku, F.A.; Apau, R. Understanding trust on social networking sites among tertiary students: An empirical study in Ghana. Appl. Comput. Inform. 2020. [CrossRef]

64. Fishbein, M.; Ajzen, I. Beliefs, Attitude, Intention, and Behavior: An Introduction to Theory and Research; Addison-Wesley: Boston, MA, USA, 1975.

65. Amin, M.; Rezaei, S.; Abolghasemi, M. User satisfaction with mobile websites: The impact of perceived usefulness (PU), perceived ease of use (PEOU) and trust. Nankai Bus. Rev. Int. 2014, 5, 258-274. [CrossRef]

66. Dixit, R.V.; Prakash, G. Intentions to use social networking sites (SNS) using Technology Acceptance Model (TAM): An empirical study. Paradigm 2018, 22, 65-79. [CrossRef]

67. Matikiti, R.; Mpinganjira, M.; Roberts-Lombard, M. Application of the Technology Acceptance Model and the TechnologyOrganisation-Environment Model to examine social media marketing use in the South African tourism industry. S. Afr. J. Inf. Manag. 2018, 20,1-12. [CrossRef]

68. Ntim, K.K.; Fombad, M. A model for open access institutional repositories usage for university libraries in Ghana. Inf. Dev. 2020. [CrossRef]

69. Ajibade, P. Technology acceptance model limitations and criticisms: Exploring the practical applications and use in technologyrelated studies, mixed-method, and qualitative researches. Libr. Philos. Pract. 2018, 1941. Available online: http://digitalcommons. unl.edu/libphilprac/1941 (accessed on 24 January 2021).

70. Jia, Y.; Zhao, Y.; Lin, Y. Effects of system characteristics on users' self-disclosure in social networking sites. In Proceedings of the 2010 Seventh International Conference on Information Technology: New Generations, Las Vegas, NV, USA, 12-14 April 2010; pp. 529-533.

71. Shen, G.C. How quality of life affects intention to use social networking sites: Moderating role of self-disclosure. J. Electron. Commer. Res. 2015, 16, 276-289.

72. Cho, Y.C.; Sagynov, E. Exploring factors that affect usefulness, ease of use, trust, and purchase intention in the online environment. Int. J. Manag. Inf. Syst. 2015, 19, 21-36. [CrossRef]

73. Kim, J.; Kim, D. The effects of perceptional factors on personal information disclosure on the web. In Proceedings of the AMCIS 2004, New York, NY, USA, 6-8 August 2004; pp. 1163-1169.

74. Koehorst, R. Personal Information Disclosure on Online Social Networks: An Empirical Study on the Predictors of Adolescences' Disclosure of Personal Information on Facebook. Available online: http:/ / essay.utwente.nl/63797/1/MSc_Ruud_H.G._Koehorst. pdf (accessed on 15 August 2020).

75. Lee, T.; Jun, J. Contextual perceived value?: Investigating the role of contextual marketing for customer relationship management in a mobile commerce context. Bus. Process Manag. J. 2007, 13, 798-814. [CrossRef]

76. Zhao, Z.; Cao, Q. An empirical study on continual usage intention of microblogging: The case of Sina. Nankai Bus. Rev. Int. 2012, 3, 413-429. [CrossRef]

77. Detlor, B.; Hupfer, M.E.; Ruhi, U.; Zhao, L. Information quality and community municipal portal use. Gov. Inf. Q. 2013, 30, 23-32. [CrossRef]

78. Baruh, L.; Secinti, E.; Cemalcilar, Z. Online privacy concerns and privacy management: A meta-analytical review. J. Commun. 2017, 67, 26-53. [CrossRef]

79. Gupta, A.; Dhami, A. Measuring the impact of security, trust and privacy in information sharing: A study on social networking sites. J. Direct Data Digit. Mark. Pract. 2015, 17, 43-53. [CrossRef]

80. Waldman, A.E. Privacy, sharing, and trust: The Facebook study. Case West. Reserve Law Rev. 2016, 67, 193.

81. Dwyer, C.; Hiltz, S.; Passerini, K. Trust and privacy concern within social networking sites: A comparison of Facebook and MySpace. AMCIS 2007 Proc. 2007, 339. Available online: https://www.researchgate.net/publication/220889809_Trust_and_ Privacy_Concern_Within_Social_Networking_Sites_A_Comparison_of_Facebook_and_MySpace (accessed on 24 January 2021).

82. Dhami, A.; Agarwal, N.; Chakraborty, T.K.; Singh, B.P.; Minj, J. Impact of trust, security and privacy concerns in social networking: An exploratory study to understand the pattern of information revelation in Facebook. In Proceedings of the 2013 3rd IEEE International Advance Computing Conference (IACC), Ghaziabad, India, 22-23 February 2013; pp. 465-469.

83. NepoleanCat. Facebook Users in Pakistan-March 2019. Available online: https://napoleoncat.com/stats/facebook-users-inpakistan/2019/03\#: \{\}:text=There\%20were\%2031\%20467\%20000,group\%20(12\%20300\%20000) (accessed on 16 August 2020).

84. Research Advisors Sample Size Table. Available online: https://www.research-advisors.com (accessed on 12 February 2020). 
85. Soroya, S.H.; Ameen, K. What do they want? Millennials and role of libraries in Pakistan. J. Acad. Librariansh. $2018,44,248-255$. [CrossRef]

86. Kanwal, S.; Pitafi, A.H.; Akhtar, S.; Irfan, M. Online self-disclosure through social networking sites addiction: A case study of Pakistani university students. Interdiscip. Descr. Complex Syst. 2019, 17, 187-208. [CrossRef]

87. Hair, J.F.; Risher, J.J.; Sarstedt, M.; Ringle, C.M. When to use and how to report the results of PLS-SEM. Eur. Bus. Rev. 2019, 31, 2-24. [CrossRef]

88. Hair, J.F., Jr.; Howard, M.C.; Nitzl, C. Assessing measurement model quality in PLS-SEM using confirmatory composite analysis. J. Bus. Res. 2020, 109, 101-110. [CrossRef]

89. Hair, J.F., Jr.; Hult, G.T.M.; Ringle, C.; Sarstedt, M. A Primer on Partial Least Squares Structural Equation Modeling (PLS-SEM); Sage Publications: New York, NY, USA, 2016.

90. Henseler, J.; Ringle, C.M.; Sarstedt, M. A new criterion for assessing discriminant validity in variance-based structural equation modeling. J. Acad. Mark. Sci. 2015, 43, 115-135. [CrossRef]

91. Hair, J.F.; Ringle, C.M.; Sarstedt, M. PLS-SEM: Indeed a silver bullet. J. Mark. Theory Pract. 2011, 19, 139-152. [CrossRef]

92. Ringle, C.M.; Wende, S.; Becker, J.M. SmartPLS 3. SmartPLS GmbH, Boenningstedt. Available online: http:/ / www.smartpls.com (accessed on 2 September 2020).

93. Awang, Z.; Ahmad, J.H.; Zin, N.M. Modelling job satisfaction and work commitment among lecturers: A case of UiTM Kelantan. J. Stat. Modeling Anal. 2010, 1, 45-59.

94. Dijkstra, T.K.; Henseler, J. Consistent partial least squares path modeling. Mis Q. 2015, 39, 297-316. [CrossRef]

95. Shmueli, G.; Sarstedt, M.; Hair, J.F.; Cheah, J.H.; Ting, H.; Vaithilingam, S.; Ringle, C.M. Predictive model assessment in PLS-SEM: Guidelines for using PLSpredict. Eur. J. Mark. 2019, 53, 2322-2347. [CrossRef]

96. Ajis, A.; Salleh, N.A.M. Core elements of motivational factors that influence Facebook users to self-disclosure. Int. J. Bus. Manag. 2020, 4, 1-11.

97. Burke, M.; Kraut, R.E. Growing closer on facebook: Changes in tie strength through social network site use. In Proceedings of the SIGCHI Conference on Human Factors in Computing Systems, Toronto, ON, Canada, 28 April-1 May 2014; pp. 4187-4196.

98. Kwon, M.; Lee, J.Y.; Won, W.Y.; Park, J.W.; Min, J.A.; Hahn, C.; Kim, D.J. Development and validation of a smartphone addiction scale (SAS). PLoS ONE 2013, 8, e56936. [CrossRef]

99. Su, C.; Chiu, C.; Chou, Y.; Chico, C. Patterns of motives for social network site use among sixth grade pupils in Taiwan. Telemat. Inform. 2018, 35, 1782-1793. [CrossRef]

100. Lin, R.; Utz, S. Self-disclosure on SNS: Do disclosure intimacy and narrativity influence interpersonal closeness and social attraction? Comput. Hum. Behav. 2017, 70, 426-436. [CrossRef] [PubMed] 